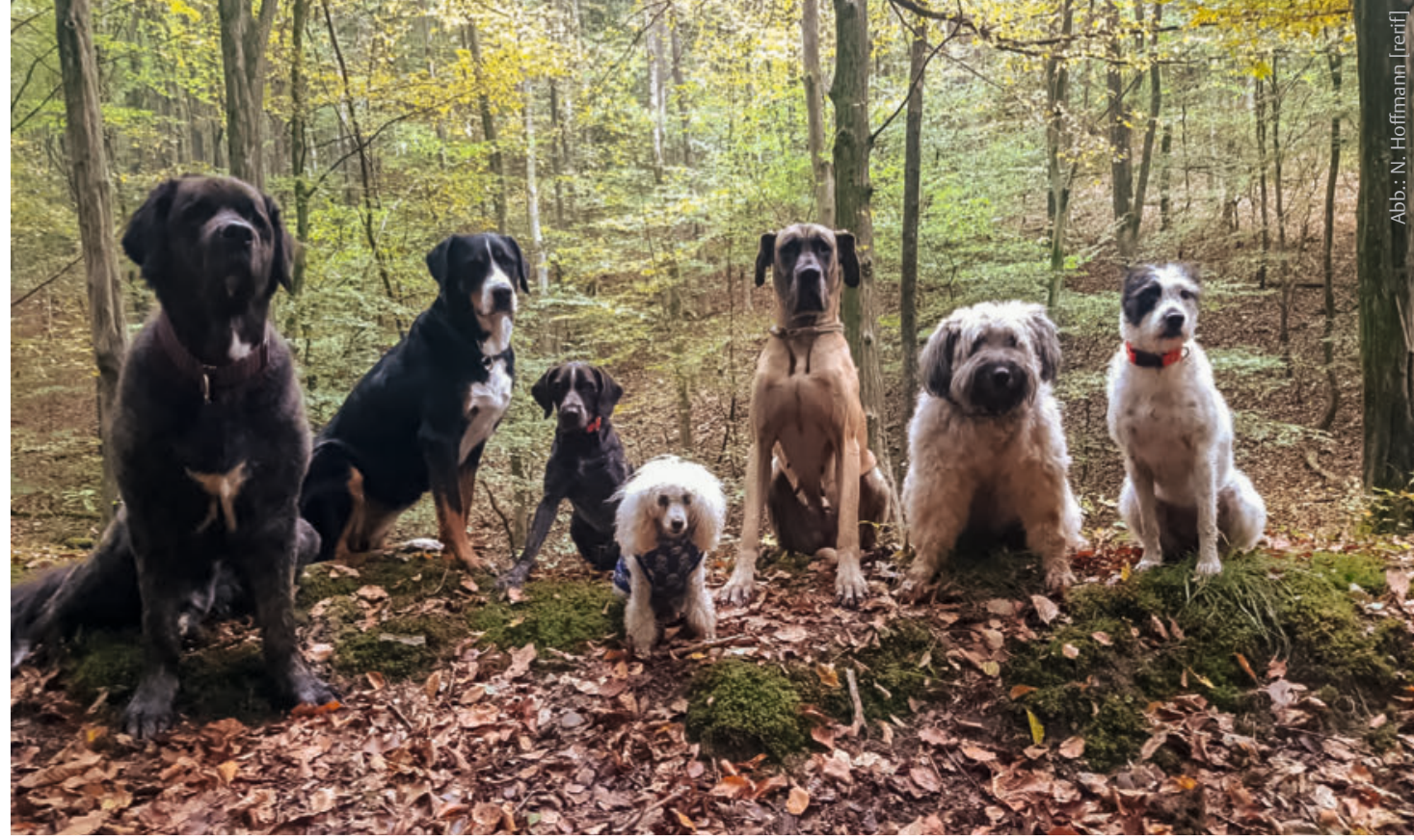

Editorial

\title{
Netzwerken auf allen Ebenen
}

Seit einigen Wochen absolviert eine angehende Ergotherapeutin ihre praktische Studienphase bei mir. Bei unserer ersten Begegnung begrüßte sie mich mit den Worten: „Dich kennt ja jeder, und nun lerne ich dich auch endlich kennen." Das habe ich bereits häufiger erlebt und wundere mich: Falle ich auf, weil ich mich so gut danebenbenehmen kann? Bin ich Influencer und weiß es nur nicht? Bezieht sich diese Bekanntheit auf mich als private Person oder auf mein berufliches Ich? Kann man das überhaupt klar voneinander trennen?

Andreas Brünen berichtet ab Seite 25 über Netzwerke. Interessanterweise habe ich ihn über mein privates Umfeld kennengelernt. Er ist der Partner meiner Hundesitterin. Schnell stellte sich heraus, dass er vor vielen Jahren an der Zuyd Hogeschool den Bachelor in Musiktherapie gemacht hat, wir beide im psychiatrischen Arbeitsfeld tätig sind und er sich vorstellen kann, $z u$ veröffentlichen. Innerhalb nur eines Gespräches entstand aus einem

$$
\begin{aligned}
& \text { "Berufliche Kontakte } \\
& \text { fördern die eigene } \\
& \text { Entwicklung und die } \\
& \text { der Profession." }
\end{aligned}
$$

privaten ein neues berufliches Netzwerk.

In seiner Beschreibung der Netzwerkebenen finde ich mich sehr gut wieder: Berufliche Netzwerke tragen zur eigenen professionellen Weiterentwicklung bei, fördern aber auch die Professionsentwicklung. Jedes Jahr freue ich mich auf Kongresse, um alte Bekannte wiederzutreffen, neue Kontakte zu knüpfen, gemeinsam die Weiterentwicklung der Ergotherapie „zu spinnen“ und voneinander zu profitieren: bestimmt nicht finanziell, sondern im Hinblick auf das Erleben sozialer Unterstützung und Entlastung sowie auf den Erhalt der professionellen Handlungsfähigkeit.

Ich hoffe, dass ich dies zurückgeben kann, zum Beispiel an meine Auszubildenden. Und damit meine ich nicht das schlechte Benehmen.

Ihre

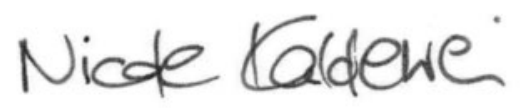

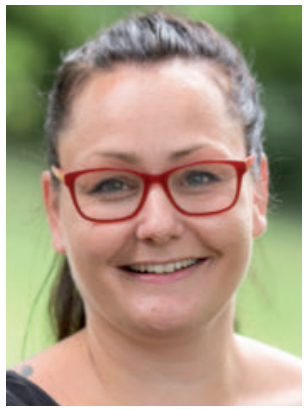

Nicole Kaldewei

Herausgeberin ergopraxis n.kaldewei@gmx.de 